\title{
Dietary Patterns as a Predictive Factor for Overweight and Obesity Among Secondary School Children in Mashhad, Iran
}

\author{
Khosro Shafaghi $\mathrm{PhD}^{1 *}$, Zalilah Mohd Shariff $\mathrm{PhD}^{2}$, Mohd Nasir Mohd Taib $\mathrm{PhD}^{2}$ and Hejar Abdul Rahman $\mathrm{PhD}^{2}$
}

${ }^{1}$ Department of Nutrition and Biochemistry, Faculty of Medicine, Gonabad University of Medical Sciences, Gonabad, Iran

${ }^{2}$ Department of Nutrition and Dietetics, Faculty of Medicine and Health Sciences, Universiti Putra Malaysia, Selangor, Malaysia
${ }^{*}$ Corresponding author

Khosro Shafaghi, PhD, Department of Nutrition and Biochemistry, Faculty of Medicine, Gonabad University of Medical Sciences,Gonabad, Iran, Tel: 0098-9151520820,E-mail: dshafaghi@yahoo.com

Submitted: 07 Aug 2018; Accepted: 15 Aug 2018; Published: 22 Aug 2018

\begin{abstract}
This cross-sectional study was carried out to determine the prevalence of overweight and obesity among secondary school children in the city of Mashhad, Iran and its association with dietary patterns. A total of 1189 secondary school children (579 males and 610 females) aged 12- 14 years old were selected through a stratified multistage random sampling. All adolescents were measured for weight and height. Household socio-demographic information were self-reported by parents. Adolescents were classified as overweight or obese based on BMI-for age Z-score. Dietary patterns were assessed using a validated Iranian food frequency questionnaire (FFQ) included 121 food items. The principal component factor analysis (PCA) was applied to derive dietary patterns, and Logistic Regression (LR) was applied to examine the association between dietary pattern and adolescents BMI. The overall prevalence of overweight and obesity among the study population was $17.2 \%$ and $11.9 \%$, respectively. The PCA analysis revealed the presence of two dietary patterns that were labeled as 'Healthy dietary pattern' (HP), and 'Unhealthy dietary pattern' (UP). LR analysis showed that HP was significantly associated with BMI (OR: 1.28, 95\% CI: 1.124-1.47). Similarly, UP was significantly associated with BMI (OR: 0.861, 95\% CI: .725-.968). In Iran, nutritional transition has taken place in the context of urbanization and has changed lifestyle, and dietary patterns. Policies must be formulated and circulated in the society to reach every family in the form of healthy dietary pattern.
\end{abstract}

Keywords: Dietary pattern, overweight, obesity, children, Mashhad

\section{Introduction}

Obesity is a public health concern across developed and developing countries. Globally, high prevalence of overweight and obesity has been explained as a pandemic in several countries [1]. Global evaluations showed that overweight and obesity were resulted in $4 \%$ of disability adjusted life-years (DALYs), $4 \%$ of years of life lost, and in 3.4 million deaths [2]. Similarly, prevalence of childhood obesity is increased globally [3]. Childhood obesity has been called "one of the most serious public health challenges of the 21st century" [3]. In developed countries, the prevalence of overweight and obesity has increased remarkably in USA [4], Canada [5], and European countries [6]. In developing countries, Sharp increase in prevalence of overweight and obesity in adolescents has been revealed in Brazil, China, and India [7]. In Australasia, Pacific Islands, China and Middle East, prevalence of obesity have rose about 3-fold since 1980 [8]. In Middle East, Kuwait, Qatar, and Iran has experienced high prevalence of overweight and obesity among adolescents [9-11].

Multiple factors contribute to childhood obesity, among them, Dietary intake is an important determinant of obesity. Dietary pattern approach is known as a usual method in nutritional epidemiology. A dietary pattern approach investigates overall dietary consumption by taking intakes of combined foods and nutrients [12]. Measuring the dietary patterns is used to evaluate the complex nature of dietary intake and investigate its relation to health. Several studies have reported the relationship between major dietary patterns with obesity and central adiposity [13, 14]. A reverse relationship has been demonstrated between eating habits and the Prevalence of overweight and obesity in children [15]. Some researchers believed that a healthful dietary pattern should include high intakes of fruit, vegetables, reduced-fat dairy products, and fiber [16].

Epidemiological studies indicate the association of dietary patterns with overweight / obesity in some populations. The dietary patterns rich in vegetable, fruits, whole grain cereals and low fat dairy, fish and beans are significantly associated with lower BMI and smaller Waist circumferences. Few studies have reported the association between dietary patterns and overweight and obesity from developing countries. The first reported investigation from the Middle-Eastern countries to identify the association of major dietary patterns with general and central obesity was done in Iran [14] that was resulted in identifying three major dietary patterns, which were labeled as the healthy, western, and Iranian Dietary pattern.

Obesity and overweight, arterial hypertension, inadequate physical activity, hypercholesterolemia, and addiction are the 5 risk factors 
causing the highest proportion of burden. Among Iranians aged 1564 years, 39\% had low levels of activity, 44\% were overweight, 15 $\%$ were obese, and $88 \%$ consumed less than 5 combined servings of fruit and vegetables per day [17]. Childhood obesity in Iran is a rising health-concern and will become the main public challenge later [18]. The rapid increase in childhood obesity in Iran reveals that environmental factors are related to this epidemic [19]. Unhealthful eating behaviors such as high consumption of fast foods, energydense snacks, sugary drinks, and other environmental factors are important contributors to childhood obesity in Iran. Sedentary lifestyle play role in relation to Iranian childhood obesity. Most of the studies in Iran have been focused on energy-dense food and macronutrients, as the main contributing factors to overweight and obesity. There are few research studies related to dietary patterns in Iran particularly among adolescents. The present study is discussed on the relationship of patterns of dietary with BMI, and WC to see whether dietary patterns are potentially contributing factors to overweight and obesity among the adolescents.

\section{Materials and Methods}

\section{Subjects}

In this study 1189 school children (579 males and 610 females) aged 12-14 years old were selected. The population of school children in Mashhad was approximately 110,000 students, in academic year of 2010-2011.The sample subjects were selected through a stratified multistage random sampling in urban low and high socio-economic area of Mashhad.

\section{Measurement}

\section{Anthropometric}

Body weight was measured to the nearest $0.1 \mathrm{~kg}$ using Healthometer (Seca Corporation) professional floor scale.

Children were required to remove their coats, shoes and to empty their pockets before measurement. Height was measured and recorded to the nearest $0.5 \mathrm{~cm}$ using a flexible non-stretchable tape (range $0-1.5 \mathrm{~m} \times 0.1 \mathrm{~cm}$; CMS

Weighing Equipment Ltd) fixed to a flat vertical wall. Children were required to take off their shoes and any head garments before measurement. Body mass index (BMI) was calculated as BMI= Body Weight $(\mathrm{kg}) /$ Height $(\mathrm{m} 2)$ and then, categorized according to the World Health Organization cut-off points (WHO, 2007) using WHO AnthroPlus software.

\section{Energy and nutrients intake}

Total energy intake, percent of energy from macronutrients (protein, fat and carbohydrate), and micronutrients (vitamin A, vitamin $\mathrm{C}$, vitamin D, Folate, Calcium, Zinc, Iodine and Sodium) were assessed using a 24-hour dietary recall and 1-day food record questionnaire.

\section{Dietary pattern}

Dietary patterns were assessed using a food frequency questionnaire (FFQ). A validated Iranian semi quantitative FFQ (Esmailzadeh et al. 2007) was used in this study including 121 food items. The questionnaire had been validated in Iran and was modified to include foods typically eaten by adolescents to assess usual dietary intake over the previous month based on a daily (e.g., bread), weekly (e.g., Kebab), or monthly (e.g., fish). Adolescents were asked by the trained interviewers how often, on average, they had consumed each food item during the month prior to the study. FFQ included type, amount and frequency of food/drink. Adolescents through FFQ were asked how often they had eat/drink this food/beverage over the last month. Nine responses were categorized ranging from 'once a day', '2-3 times in a day' ' $4-6$ times in a day' ' 1 time in a week', '2-3 times in a week', '4-6 times in a week', '1-3 times in a month', 'rarely eaten', to 'never eaten'.

\section{Socio-demographic}

Socio-demographic background of the children including age, sex, and birth order were determined through a face to face interview. The education and occupation of their parents, family size, and family monthly income were obtained through parents' self-administered questionnaire.

\section{Data analysis}

Principal component analysis (PCA)

Prior to performing the principal component analysis (PCA), the suitability of data for factor analysis was assessed. Inspection of the correlation matrix on the food group variables revealed the presence of several correlation coefficients of 0.2 and above. The KaiserMeyer-Oklin value was 0.781 , which exceeded the recommended value of 0.6 and the Barlett's Test of Sphericity reached the statistical significance supported the factorability of the correlation matrix.

The principal component factor analysis was applied to derive dietary patterns on the basis of 29 food groups. FFQ data was applied to find food consumption "factors" (or patterns) of adolescents. Foods or food groups were placed in "factors" based on their correlation degree [20]. A number of servings per day for each food group variable were calculated as the input value for the factor analysis. Every food group variable that met the criteria with communality of $>0.3$ had sufficient explanation. The variables $<0.3$ were eliminated from further analysis. In determining the number of factors to retain, a stepwise process was utilized. The factors were rotated by orthogonal transformation (Varimax rotation) to achieve a simpler (non-overlapping) structure with greater interpretability. The next step was labeling the retained factors. Dietary patterns were called reflecting food groups having the highest loadings on that factor. Food group variables having a positive loading on a factor contributed directly to that dietary pattern, whereas those with negative loading were inversely associated with a given dietary pattern. The factor score indicated the extent to which individual's diet conformed in one of the dietary patterns. A higher value of the factor score (either positive or negative) indicated high or low intake of the food group constituting that food pattern. Then the factor score was used to represent the factors in subsequent analysis.

Diet Plan6.60 software was used to analyze the energy and macro/ micronutrient intake of the adolescents. The software included long food list specifically like the most Iranian foods. Persian food/ snacks and portion size were converted to the available menu in Diet Plan6.60. Adolescents' nutrient intake was compared to WHO/ FAO [21].

\section{Results}

The study showed that $11.7 \%$ of respondents were obese (BMI Z-score $>+2$ SD) and $17.3 \%$ were overweight (BMI Z-score between $+1 \mathrm{SD}$ and $<+2 \mathrm{SD})$. A higher proportion of males $(30.7 \%)$ than females $(27.4 \%)$ were overweight or obese. The differences between males and females were significant $(\mathrm{p}<0.02)$. 
The Principal Component Factor analysis was applied to define dietary patterns among the study subjects based on 29 food group variables. A total of 121 items in food frequency questionnaire were consolidated into 29 food groups based on their macronutrient profile (Table 1). The Principal component analysis revealed the presence of two factors or dietary patterns with eigenvalues exceeding 1 explaining 26.6 percent of the variance in original dietary intake. An inspection of the scree plot revealed a clear break after the second factor indicating retention of two factors.

Table 1: Food Groupings of Food Items

\begin{tabular}{|c|c|c|}
\hline \multicolumn{2}{|c|}{ Food group } & \multirow{2}{*}{$\begin{array}{l}\text { Examples of food items } \\
\text { Kielbasas, sausage, hamburger }\end{array}$} \\
\hline 1 & Processed Meat & \\
\hline 2 & Red Meat & Beef, lamb \\
\hline 3 & Organ Meats & Heart and liver, heart and trotter \\
\hline 4 & Fish\& sea food & Canned Tunna fish, other fishes, shrimp \\
\hline 5 & Poultry & Chicken \\
\hline 6 & Egg & Boiled egg, fried egg \\
\hline 7 & Low fat dairy & $\begin{array}{l}\text { Low fat milk, low fat yogurt, dough, } \\
\text { pasteurized whey }\end{array}$ \\
\hline 8 & High fat dairy & $\begin{array}{l}\text { Whole milk, chocolate milk, cream, pizza } \\
\text { cheese, pasteurized ice cream, traditional } \\
\text { ice cream }\end{array}$ \\
\hline 9 & Tea\& Coffee & Tea, coffee \\
\hline 10 & Fruit & $\begin{array}{l}\text { Pears, apricot, cherry, apples, grapes, } \\
\text { bananas, cantaloupe, watermelon, } \\
\text { oranges, grapefruit, kiwi, strawberries, } \\
\text { peaches, plums, persimmons, sweet } \\
\text { lemon, pineapples, fresh fig, dates, olive }\end{array}$ \\
\hline 11 & $\begin{array}{l}\text { Fruit } \\
\text { juice (Unsweetened) }\end{array}$ & $\begin{array}{l}\text { Apple juice, orange juice, grapefruit juice, } \\
\text { carrot juice }\end{array}$ \\
\hline 12 & Green vegetables & $\begin{array}{l}\text { Lettuce, spinach, mixed vegetables, } \\
\text { celery, green pepper , Cabbage, garlic, } \\
\text { turnip, cucumber }\end{array}$ \\
\hline 13 & White vegetables & Cabbage, garlic, turnip \\
\hline 14 & Yellow vegetables & Carrot, tomato, tomato sauce \\
\hline 15 & Potato & Cooked potato, fried potato \\
\hline 16 & Legumes & Beans, pea, lentils \\
\hline 17 & Whole grains & $\begin{array}{l}\text { Traditional bread, barley bread, Sangak } \\
\text { bread, Taftoon bread }\end{array}$ \\
\hline 18 & Refined grains & $\begin{array}{l}\text { White bread, lavash bread, Barbari bread, } \\
\text { sweet bread, rice, Reshteh, spaghetti, } \\
\text { biscuits }\end{array}$ \\
\hline 19 & Pizza & Pizza \\
\hline 20 & Snacks & Potato chips, pofak (corn puff) \\
\hline 21 & Nuts & Almond, pistachio roasted seed, walnut \\
\hline 22 & Mayonnaise & Mayonnaise sauce \\
\hline 23 & $\begin{array}{l}\text { Dried\& processed } \\
\text { fruits }\end{array}$ & $\begin{array}{l}\text { Dried fig, dried date, dried mulberries, } \\
\text { resins, fruit conserved }\end{array}$ \\
\hline 24 & Sweets & $\begin{array}{l}\text { Cookies, kolocheh, Yazdi cake, dry } \\
\text { pastries, creamed pastries }\end{array}$ \\
\hline 25 & $\begin{array}{l}\text { Sugars\& } \\
\text { confectionary }\end{array}$ & $\begin{array}{l}\text { Cube sugar, candies, cocoa chocolate, } \\
\text { Jam, honey }\end{array}$ \\
\hline 26 & $\begin{array}{l}\text { Soft\& sweetened } \\
\text { drinks }\end{array}$ & $\begin{array}{l}\text { Gaseous drinks, Delester, Maoshair, } \\
\text { sundis (industrial fruit juice) }\end{array}$ \\
\hline
\end{tabular}

J Nur Healthcare, 2018

\begin{tabular}{|l|l|l|}
\hline 27 & $\begin{array}{l}\text { Broth (Fatty Iranian } \\
\text { chew) }\end{array}$ & Broth \\
\hline 28 & Pickles & $\begin{array}{l}\text { Pickles, Shoor (salty fermented } \\
\text { vegetables), salted cucumber }\end{array}$ \\
\hline 29 & Oils\& Fats & $\begin{array}{l}\text { Vegetable oils, hydrogenated oils, animal } \\
\text { oils, olive oils, butter }\end{array}$ \\
\hline
\end{tabular}

Using the Catell's scree test, two components were retained for further investigation. In order to aid in interpretation of these two factors or dietary patterns, Varimax rotation was performed. The rotated solution resulted in a simple structure of the two dietary patterns with strong loadings of particular food items. The factor loading matrices for the 2 dietary patterns are shown in Table 2 . The patterns were labelled subjectively based on the nature of the food groups with high loadings in each dietary pattern. The first pattern was labelled "Healthy dietary pattern". It was characterized by higher intake of fish and other sea foods, fruits, and fruit juice, green, white and yellow vegetables, whole grains, dried and processed fruits. The second dietary pattern was heavily loaded on sweets, sugars and confectionary, tea, and coffee, egg, cooked, and fried potato, and moderately loaded on snacks, nuts, Iranian broth, and pickles. This second pattern was named as "Unhealthy dietary pattern" because the food items of the pattern are high energy dense and rich in oil and sugar. The healthy dietary pattern explained $20.2 \%$ of the variance in dietary intake while unhealthy dietary pattern explained $6.4 \%$ of the variance. Together, the 2 factors or dietary patterns accounted for $26.4 \%$ of the variances in dietary pattern.

Table 2: Factor Loading Matrix For Two Identified Dietary Patterns

\begin{tabular}{|l|l|c|c|}
\hline \multicolumn{2}{|l|}{ Food groups } & Factors and factor loading \\
\cline { 3 - 4 } \multicolumn{2}{|l|}{$\begin{array}{c}\text { Healthy } \\
\text { pattern }\end{array}$} & $\begin{array}{c}\text { Unhealthy } \\
\text { pattern }\end{array}$ \\
\hline 1 & Processed meats & & \\
\hline 2 & Red Meats & 0.474 & \\
\hline 3 & Organ meats & 0.439 & 0.362 \\
\hline 4 & Fish\& sea foods & & \\
\hline 5 & Poultry & & 0.466 \\
\hline 6 & Eggs & & \\
\hline 7 & Low fat dairy & & 0.518 \\
\hline 8 & High fat dairy & & \\
\hline 9 & Tea\& Coffee & 0.637 & \\
\hline 10 & Fruits & 0.665 & \\
\hline 11 & Fruit juice (Unsweetened) & 0.520 & \\
\hline 12 & Green vegetables & 0.530 & \\
\hline 13 & White vegetables & 0.481 & \\
\hline 14 & Yellow vegetables & & 0.427 \\
\hline 15 & Potato & & \\
\hline 16 & Legumes & & \\
\hline 17 & Whole grains & & \\
\hline 18 & Refined grains & & \\
\hline 19 & Pizza & & \\
\hline 20 & Snacks & & \\
\hline 21 & Nuts & & \\
\hline
\end{tabular}

Volume 3 | Issue 3 | 3 of 6 


\begin{tabular}{|c|l|c|c|}
\hline 22 & Mayonnaise & 0.414 & \\
\hline 23 & Dried \& processed fruits & 0.483 & \\
\hline 24 & Sweets & & 0.578 \\
\hline 25 & Sugars \& confectionary & & 0.666 \\
\hline 26 & Soft\& sweetened drinks & & 0.373 \\
\hline 27 & $\begin{array}{l}\text { Broth } \\
\text { (Fatty Iranian chew) }\end{array}$ & 0.469 \\
\hline 28 & Pickles & & 0.439 \\
\hline 29 & $\begin{array}{l}\text { Oils\& fats Explained } \\
\text { Variances by each factor }\end{array}$ & 20.2 & 6.4 \\
\hline
\end{tabular}

low intake of sweetened drinks, other sweets, fried foods, burgers, and pizza. In the whole cohort studies on Swedish women, the researchers identified 3 major dietary patterns that were termed "Healthy," "Western," and "Drinker" patterns [29]. In a study in Iran [14], three major dietary patterns were extracted and were labeled: the healthy dietary pattern, the western dietary pattern, and the Iranian dietary pattern. In another study on adolescent girls aged 11-15 in Tabriz, Iran, 6 major dietary patterns were identified [30]. In a cross-sectional study conducted in Isfahan, Iran, with 637 elementary school-age children, three major dietary patterns were extracted: "Healthy," "Western," and "Sweet-Dairy." [31].

Logistic Regression (LR) was applied to examine the association between dietary pattern and BMI. The Principal component analysis revealed the presence of two dietary patterns, including Healthy dietary pattern (HP), and Un-healthy dietary pattern (UP). The results showed that HP was significantly associated with BMI (OR: 1.28, 95\% CI: 1.124-1.47). Similarly, UP was significantly associated with BMI (OR: 0.861, 95\% CI: .725-.968) (Table 3).

Table 3: Logistic Regression (LR) Between Dietary Pattern and BMI

\begin{tabular}{|c|c|c|c|c|c|c|}
\hline $\begin{array}{c}\text { Dietary } \\
\text { pattern }\end{array}$ & $\begin{array}{c}\text { Overweight/ } \\
\text { obesity }\end{array}$ & $\begin{array}{c}\text { Correlation } \\
\text { Coefficient }\end{array}$ & OR & SE & $\mathbf{9 5 \%}$ CI & p value \\
\hline HP & BMI & .253 & 1.288 & .069 & $1.124-1.47$ & .000 \\
\hline UP & BMI & -.410 & .664 & .073 & $.575-0.766$ & .000 \\
\hline
\end{tabular}

Mean values for energy and nutrient intakes were compared with recommended nutrient intake (RNI) for the United Kingdom (Food Standards Agency, 2006). The mean energy intake for male and female adolescents were $2400 \mathrm{kcal}(\mathrm{SD}=656)$ and $2375 \mathrm{kcal}$ $(\mathrm{SD}=535)$, respectively. The mean energy intake was much higher as compared to RNI whereby in this age group, energy requirement is recommended as $2220 \mathrm{kcal}$ for males and $1845 \mathrm{kcal}$ for females. The mean protein intake of adolescents was much higher as compared to RNI. Protein, fat and carbohydrate energy contributor was approximately adapted to RNI.

\section{Discussion}

Most of the studies investigating the dietary patterns have been conducted in developed countries. It was only in the last decade that studies started to be conducted in developing countries. Many dietary patterns are known globally. The Mediterranean dietary pattern has been associated with a decrease in overall mortality [22, 23].Besides, Okinawan diet that is popular in Okinawa, the southernmost part of Japan, accompanying low risk of age-associated diseases. Low levels of saturated fat, high antioxidant intake, and low glycemic load in these diets probably contribute to a decreased risk for cardiovascular disease, some cancers, and other chronic illnesses [24].

Maria Teresa et al [25] identified two main dietary patterns as common Brazilian and processed food. Shin et al. [26] reported 3 major dietary patterns: Korean healthy pattern, Animal food pattern, and Sweet pattern. McNaughton et al. (2008) identified 3 dietary patterns labeled as fruit, salad, cereals and fish pattern; a high fat and sugar pattern, and a vegetable pattern. Lozada et al. [27] identified 4 major dietary patterns. Ritchie et al. [28] showed that the healthy pattern was the characteristic of high intake of fruits, vegetables, dairy, grains without added fats, mixed dishes and soups, and a

In current study, the principal component analysis revealed the presence of two dietary patterns with eigen values exceeding 1 , explaining 26.6 percent of the variances in the original dietary intake. The patterns were labeled subjectively based on the nature of food groups with high loadings in each dietary pattern. The healthy dietary pattern explained $20.2 \%$ of the variances in dietary intake, while unhealthy dietary pattern explained $6.4 \%$ of the variance. Logistic regression analysis (LR) showed that healthy pattern was significantly associated with BMI (OR: 1.28, 95\% CI: 1.124-1.47). Unhealthy Pattern was also significantly associated with BMI (OR: 0.861, 95\% CI: .725-.968). Several studies have reported the association of major dietary patterns with obesity [13, 32]. In a study on 1,072 adults living in two different districts of Ouagadougou, Montpellier, France, the first two components of the principal component analysis were interpreted as a "snacking" score a "modern foods" score, respectively. Besides, a higher "modern foods" score was associated with a higher prevalence of overweight but there was no relationship between overweight and the "snacking" score [33]. Examining dietary patterns in 1139 fourteen-year-olds in Western Australia, showed that higher 'Western' dietary pattern scores were associated with greater odds for BMI in girls [34]. But, Carrera et al [35] stated that BMI did not differ significantly with respect to all four dietary patterns. A study in Iran showed that individuals in the upper category of the healthy pattern score were less likely to be obese, whereas those in the upper quintile of western pattern had greater odds for obesity [14]. Bahreynian et al [31] found significant relationships between adherence to healthy pattern and BMI. They showed that overweight girls were more likely to have a western or sweet dairy pattern.

In Iran, nutritional transition has taken place within the context of a rapid demographic change, urbanization and social development [36].Per capita daily energy increased from $1772 \mathrm{kcal}$ in 1961 to $3044 \mathrm{kcal}$ in 2007 . At the national level, the average energy and protein intakes are higher than the respective RDAs. Per capita daily energy supplied by cereals declined from about $60.3 \%$ in 1961 to $50.6 \%$ in 2007 . The daily protein supply through animal products increased from $26.48 \%$ in 1961 to $28.49 \%$ in 2007 . Per capita energy consumption increased from $650 \mathrm{~kg}$ in 1970 to $2,438 \mathrm{~kg}$ in 2005 based on $\mathrm{kg}$ of oil equivalent (FAO, 2007). An increasing rate of urbanization and changing lifestyles in Iran increased the risk of overweight and obesity in children [37].

\section{Conclusion}

Dietary pattern analysis is a useful way to summarize overall dietary intake. This method allows us to examine total diet which is contrast to the traditional method of examining single nutrients, foods or food groups. Dietary patterns are useful when a researcher wants to examine the relationship between overall patterns of diet and health 
outcomes, such as obesity. Dietary pattern representing a broader picture of foods and nutrients consumption that are modulated by genetics, culture, society, health, environment, lifestyle, and economics.

The present study has highlighted the common dietary patterns among adolescents in urban population in Mashhad. These patterns were "healthy" and "unhealthy" patterns mainly reflecting Iranian foods. On the other hand, the overall prevalence of overweight and obesity among secondary school children in Mashhad was $17.2 \%$ and $11.9 \%$, respectively. Current study among a population of 1189 adolescents selected from a large population-based sample of secondary school children in Mashhad, has identified distinct dietary patterns which show relationships with some socioeconomic, lifestyle-related, eating behavior factors, and obesity. Thus, it may have important implications for the improvement of diet and lifestyle behaviors. The issue requires mass awareness and persistent efforts to bring about a significant change. It should be made a public health priority and forces from all the disciplines to formulate an effective health campaign. Programs and policies have to be formulated and circulated in the society to reach every family. Families have to include discipline in their existing lifestyles in the form of healthy dietary pattern. Childhood obesity is one of the biggest health issues in Mashhad. The high prevalence of overweight and obesity among secondary school children could be related to the changing lifestyle of the population. Strategies to address childhood obesity should consider the interaction of these factors and its impact on lifestyle behaviors of children and adolescent.

\section{Acknowledgment}

This research project has been supported by Department of Biochemistry \& Nutrition, Mashhad University of Medical Sciences, and also by the Research Center of Education and Training Organization of Khorasan Razavi, both are gratefully acknowledged.

\section{Ethical Consideration}

The study protocol was approved by the medical research ethics committee (Faculty of Medicine and Health Sciences, UPM). Written informed consent was obtained from the parents on behalf of the children involved.

\section{Author Disclosures}

The authors declare that they have no conflict of interests.

\section{References}

1. Popkin BM, Adair LS, Ng SW (2012) Global nutrition transition and the pandemic of obesity in developing countries. Nutr Rev 70: 3-21.

2. Lim SS, Vos T, Flaxman AD (2012) A comparative risk assessment of burden of disease and injury attributable to 67 risk factors and risk factor clusters in 21 regions, 1990-2010: a systematic analysis for the Global Burden of Disease Study 2010. Lancet 380: 2224-60.

3. World Health Organization (2012) Global strategy on diet, physical activity, and health: childhood overweight and obesity. Cited in: www. Int/dietphysicalactivity/childhood/en/. Accessed March 9, 2012.

4. Ogden CL, Carroll MD, Kit BK, Flegal KM (2012) Prevalence of obesity and trends in body mass index among US children and adolescents, 1999-2010. JAMA 307: 483-490.

5. Public Health Agency of Canada (2011) Obesity in Canada:
A Joint Report from the Public Health Agency of Canada and the Canadian Institute for Health Information. In: 2011: 12-6.

6. Lien N, Henriksen HB, Nymoen LL, Wind M, Klepp KI (2010) Availability of data assessing the prevalence and trends of overweight and obesity among European adolescents. Pub Health Nutr13: 1680-1687.

7. Bhardwaj S, Misra A, Khurana L, Gulati S, Shah P, et al. (2008) Childhood obesity in Asian Indians: a burgeoning cause of insulin resistance, diabetes and sub-clinical inflammation. Asia Pac J Clin Nutr 17 Suppl 1: 172-175.

8. World Health Organization (2008) Report of the World Health Organization Study Group. Diet, nutrition and prevention of chronic diseases.

9. Marie Ng, Tom Fleming, Margaret Robinson, Blake Thomson, Nicholas Graetz, Christopher Margono Global, regional, and national prevalence of overweight and obesity in children and adults during 1980-2013: a systematic analysis for the Global Burden of Disease Study 2013 Volume 384, Issue 9945, 30 August-5 September 2014, Pages 766-781

10. Bener A (2006) Prevalence of obesity, overweight, and underweight in Qatari adolescents. Food Nutr Bull 27: 39-45.

11. Moayeri H, Bidad K, Aghamohammadi A, Rabbani A, Anari S, Nazemi L et al. ( 2006) Overweight and obesity and their associated factors in adolescents in Tehran, Iran, 2004-2005. Eur J Pediatr 65: 489-93.

12. Moller SM, Reedy J, Millen A (2007) Dietary patterns: Challenges and opportunities in dietary pattern research. $\mathrm{J}$ Am Diet Asso107: 1233-1239.

13. McNaughton SA, Mishra GD, Stephen AM, Wadsworth MEJ (2007) Dietary patterns throughout adult life are associated with body mass index, waist circumference, blood pressure and red cell folate. J Nutr 137: 99-105.

14. Esmaillzadeh A, Azadbakht L (2008) Major dietary patterns in relation to general obesity and central adiposity among Iranian women. J Nutr 138: 358-363.

15. Wurbach A, Zellner K, Kromeyer-Hauschild K (2009) Meal patterns among children and adolescents and their associations with weight status and parental characteristics. Pub Health Nutr 12: $1115-1121$

16. McNaughton SA, Ball K, Mishra GD, Crawford DA (2008) Dietary patterns of adolescents and risk of obesity and hypertension. J Nutr 138: 364-370.

17. Ministry of Health and Medical Education (2009) Deputy of Health Center, Center for NCD control and prevention, NCD risk factors surveillance office, report on NCD risk factors 2006-2009.

18. World Health Organization (2007) BMI for age, girls 5 to 19 years Z-Score.

19. Maddah M, Rashidi A, Mohammadpour B, Vafa R, Karandish M (2009) In-school snacking, breakfast consumption and sleeping patterns of normal and overweight Iranian high school girls: A study in urban and rural areas in Guilan, Iran. J Nutr educ Behav 41: 27-31.

20. Esmaillzadeh A, Mirmiran P, Azizi F (2005) Whole-grain intake and the prevalence of hypertriglyceridemic waist phenotype in Tehranian adults. Am J Clin Nutr 81: 55-63.

21. World Health Organization (2004) Obesity: preventing and managing the global epidemic. Report of WHO Consultation. Geneva 2004.

22. Pagona Lagiou, Dimitrios Trichopoulos, Sven Sandin, Areti Lagiou, Lorelei Mucci, et al.(2006) Mediterranean dietary 
pattern and mortality among young women: a cohort study in Sweden British Journal of Nutrition 96: 384-392.

23. Panagiota N. Mitrou, Victor Kipnis, Anne C. M. Thie'baut, Jill Reedy, Amy F, et al (2007) Mediterranean Dietary Pattern and Prediction of All-Cause Mortality in a US Population Results From the NIH-AARP Diet and Health Study Arch Intern Med 167: 2461-2468.

24. D. Craig Willcox, Bradley J. Willcox, Hidemi Todoriki, Makoto Suzuki (2009) The Okinawan Diet: Health Implications of a Low-Calorie, Nutrient-Dense, Antioxidant-Rich Dietary Pattern Low in Glycemic Load Journal of the American College of Nutrition 28: 500S-516S.

25. Teresa MA, Olinto, Denise P, Gigante, Horta B, et al. (2012) Major dietary patterns and cardiovascular risk factors among young Brazilian adults Eur J Nutr 51: 281-291.

26. Shin KO, Oh S, Park HS (2007) Empirically derived major dietary patterns and their associations with overweight in Korean preschool children. Br J Nutr 98: 416-421.

27. Lozada AL, Flores M, Rodríguez S, Barquera S (2007) Dietary patterns in Mexican adolescent girls. A comparison of two methods. National Nutrition Survey, 1999. Salud Publica Mex 49: 263-273.

28. Ritchie LD, Spector P, Stevens MJ, Schmidt MM, Schreiber GB, et al. (2007) Dietary Patterns in Adolescence Are Related to Adiposity in Young Adulthood in Black and White Females. J Nutr 137: 399-406.

29. Rashid Khani B, Ye W, Terry P, Wolk A (2004) Reproducibility and validity of major dietary patterns among Swedish women assessed with a food-frequency questionnaire. J Nutr 134:
1541-1545.

30. Alizadeh M, Mohtadinia J, Pourghasem-Gargari B, Esmaillzadeh A (2012) Major dietary patterns among female adolescent girls of Talaat intelligent guidance school, Tabriz, Iran. Iran Red Crescent Med J 14: 436-441.

31. Maryam Bahreynian, Zamzam Paknahad, and Mohammad Reza Maracy Major Dietary Patterns and Their Associations with Overweight and Obesity Among Iranian Children.

32. Newby PK, Weismayer C, Akesson A, Tucker KL, Wolk A (2006) Long-term stability of food patterns identified by use of factor analysis among Swedish women. J Nutr 136: 626-633.

33. Becquey E, Savy M, Danel P, Dabiré HB, Tapsoba S, MartinPrével Y (2010) Dietary patterns of adults living in Ouagadougou and their association with overweight. Nutr J 9: 13.

34. Ambrosini GL, Oddy WH, Robinson M, O'Sullivan TA, Hands BP, de Klerk NH, et al.(2009) Adolescent dietary patterns are associated with lifestyle and family psycho-social factors. Public Health Nutr 23: 1-9.

35. Carrera PM, MS, Gao X, PhD, Tucker K L (2007) A Study of dietary patterns in the Mexican-

36. Ghassemi H, Harrison G \& Mohammad K (2002) An accelerated nutrition transition in Iran .Public Health Nutrition 5: 149-155.

37. Hajian-Tilaki K, Heidari B (2013) Childhood obesity, overweight, Socio-demographic and life style determinants among preschool children in Babol, Northern Iran. Iranian J Publ Health 42: 1283-1291.
Copyright: @2018 Khosro Shafaghi, et al. This is an open-access article distributed under the terms of the Creative Commons Attribution License, which permits unrestricted use, distribution, and reproduction in any medium, provided the original author and source are credited. 